\title{
The Impact of Trust on Performance in a Supply Chain: Bridging the Gap Between Reliability and Power
}

\author{
Carmella D. Lennon ${ }^{1}$ \\ ${ }^{1}$ College of Business Administration, Jackson State University, Jackson, Mississippi \\ Correspondence: Carmella D. Lennon, College of Business Administration, Jackson State University, Jackson, \\ Mississippi, USA.
}

Received: August 12, 2019

Accepted:September 30, 2019

Online Published: October 9, 2019

doi:10.5430/jbar.v8n2p15

URL: https://doi.org/10.5430/jbar.v8n2p15

\begin{abstract}
Overtime, as trends are steady changing, companies are steady growing. From online business to multiple locations across the globe, companies are not just growing in revenue and reputation but also in staff. Most companies focus on building processes and relationships amongst staff through thorough communication. However, sometimes, it can be difficult in implementing processes and relationships with staff due to reliability and power. With these two factors, many people can either thrive in their interactions or otherwise, be unsuccessful.

In many studies, reliability and power are two known components that helps reflect performance in a supply chain. However, what bridges the gap between reliability and power? What makes an individual validate a person as reliable and powerful? What makes a process implemented in the supply chain reliable and powerful? This paper implies that trust is a component that bridge the gap between the two constructs. An individual or process that is reliable will often be trusted and obtain powerful exchanges. This paper will address and evaluate the relationship between trust, power, and reliability. The paper will briefly show a constructed model to illustrate the relationship between the variables and how it affects performance in a supply chain. Next, limitations of research will be addressed followed by suggestions for future research.
\end{abstract}

Keywords: power, trust, reliability, supply chain, management, performance

\section{Introduction}

Amazon is the world's largest online retailer, cloud service provider, and multinational technology company in the world. The company supply chain is very detailed and one of the most significant attributes of the company. The components of the company supply chain have certainly provided the company a competitive advantage over their competitors like E-bay and Wal-Mart. Many third parties' partner with the company through trust as the company have built a reputation of satisfaction, fast delivery times, and great customer service. This advantage gives Amazon supply chain power. This paper helps readers understand how variables such as reliability and power are complimented in a good performing supply chain such as Amazon's. On the other hand, it also provides a linkage on what bridges both reliability and power which is trust. This paper is a proposal to the gap in hopes of helping supply chains better perform in their competing firms. There are very few studies that identify the gap of reliability and power and how it can affect the level of trust in a firm.

The paper will address a in depth literature review that will describe all three variables and its impact on the supply chain. The two research questions in this study are (a) how does trust bridge the gap between reliability and power, (b) how is reliability positively related to trust that leads to higher power? Next, the paper will provide propositions for the study followed by implications for future research and limitations.

\subsection{Significance of the Study}

There are various studies that emphasis the importance of reliability and power implementations regarding supply chain networks. However, there are not many studies that define, elaborate, or extend research on what helps build, support, and influence reliability and power in a relationship or process. This study provides research and explanation on how trust may play a vital role in the supply chain network. With the data, model, and propositions included, this paper will add significance to the field of literature by adding trust as a strong component in relationship and process building in a supply chain. 


\subsection{Methodology Framework}

This study uses a qualitative research design. More emphasis is placed on qualitative research as much of the information presented will infer and describe meaning and objectives of the paper using a conceptual overview. Inferences from the conceptual data will help develop an analysis that supports the purpose of the study and show trust bridges the gap between reliability and power in a supply chain.

A total of 15 references were used to collect the data shown in the paper. The information collected to obtain data in the paper will be taken from articles, surveys, and questionnaires. Some of the information was also collected as secondary sources given that the researcher made comments from primary sources. The information was collected from valuable resources between the years of 2000 and 2017.

\section{Literature Review}

\subsection{Supply Chain}

A supply chain is the network of all the individuals, organizations, resources, activities and technology involved in the creation and sale of a product, from the delivery of source materials from the supplier to the manufacturer, through to its eventual delivery to the end user (Rouse, 2013). Supply chains are critical to a business as it is the peak of success. The more in-tact and strong a supply chain is, the better the performance of the supply chain, meaning the company will have a strong competitive advantage. Supply chain professionals are often the last line of defense in the face of disruption, having to analyze and react to adverse circumstances quickly (Lopez, 2017). Because the job and duties of these professionals are so intense, the relationship between processes and individuals are important to consider when determining the overall performance and success of a business.

We then begin to discuss supply chain management (SCM) which is the management of supply chains activities to maximize customer value and achieve a sustainable competitive advantage (SME, 2017). The article, "What is Supply Chain Management," declares, organizations that make up the supply chain are allied through physical and information flows. Physical flows are the transformation, movement, and storage of goods and materials, the most visible piece of the supply chain (Amirul Mustofa, 2017). Information flows are the supply chain partners who coordinate their long-term plans to control the day to day flow of goods and materials throughout the supply chain (SME, 2017).

\subsection{Reliability}

Earlier, we discussed supply chain professionals. It is a professional top priority to increase reliability, reduce inventory and prepare for demand (Supply Chain Management Best Practices: Realibility , 2016). Because of this, supply chain reliability refers to the degree to which a supply chain yields consistent performance (What is Reliability in Supply Chain Management?, 2016). It is important to note that reliability is esteemed from honesty and integrity as these two variables must be consistent for a relationship to be reliable.

Reliability is reflective of ongoing interactions between individuals. By this, once a supply chain uses a process several times, the firm would be able to rate their expectations on the product as either reliable or not reliable. Top-quartile performance is not possible without reliable people, processes, and equipment. Everyone and everything must be reliable to provide a highly reliable supply-chain process (Blache, 2017). A product or service that function with $80 \%$ reliability, we can assume it will function $80 \%$ of the time and will overall produce dependable and consistent results. Reliability helps improve competition, performance, and quality of relationship and processes implementations (Blache, 2017).

\subsection{Power}

Power is a multi-dimensional construct. It can be best defined as the ability of a firm to own and control critical assets in markets and supply chains that allow it to sustain its ability to appropriate and accumulate value for itself by constantly leveraging its customers, competitors, and suppliers (Cox, 2002). Power influence others' behavior or the course of events in a supply chain (Ketchen, 2015). To understand power, we must first understand the five different types of power. The first type of power is reward power. This power is the ability of the source. For example, the customer, to go in the future more often in business with the target being the manufacturer (Benton, 2000). When a firm have access to resources that are valuable to supply chain professionals, this type of power persuades personnel to work in a certain way (Hanf, 2011). The second type of power is coercive power which exists when the customer has the ability to provide punishments. This means that the customer is able to stop the business activities with the manufacturer (Flynn, 2008). Coercive in supply chain is reflected by the fear of a network member being punished if the process or machine implemented fails to comply with the requirements of the focal company (Hanf, 2011). Third, 
expert power takes place when the customer has the knowledge, the expertise or the skills which are needed or desired by the manufacturer (Zhao, 2008). Expert power is achieved when supply chain professionals believe that their process or machine implementation possess a valuable, unique, and knowledge product or service. Next, referent power is the desire of one company to identify with another company (manufacturer and customer) for recognition by association (Benton, 2000). Occasionally, this happens when the supply chains are appealing to others by influencing other network actors to want to join another network. Legitimate power, meaning the natural power that a company possesses (Flynn, 2008), whereby the target is of the opinion that the source has the right to obtain influence (Benton, 2000), and make specific decisions (Hanf, 2011).

Power in a supply chain encompasses an influence that can be used to evoke desired actions from partners. Powerful firms understand the need to cooperate with others to continuously update their resource stocks and maintain scarcity through cultural competitiveness (Ireland, 2006). Power maintains a supply chain entrepreneurial orientation and ability to adapt. The advantages of power are that it provides unlimited opportunities and create channels of networking. Power is respected in a supply chain as it is supported by reliability.

\subsection{Trust}

When trusting partners, the decision to rely on a partner is the expectation that the partner will act according to a common agreement that will potentially achieve efficiency goals and the expected benefits of the transaction exceed the expected cost (Ireland, 2006). Trust is a range of observable behaviors and a cognitive state that encompasses predictability (SME, Trust in Supply Chain Relationships: What Does It Mean to Trust? - Part I, 2003). As we can imagine, trust is not an overnight process, but is built through time with repeated interactions. For example, suppose a company that sells furniture repeatedly have issues with a supplier who provides tables. After many failed encounters with the supplier, the company will then proceed to find business with a different partner who serve their needs best. The trust is built through several interactions. Trust in a supply chain is a process, but once an individual or process that carries out an activity is trusted, that then builds power in the supply chain.

There are three types of trust known as contractual, competence, and goodwill trust. Contractual trust entails a mutual understanding by partners to an agreement (Ireland, 2006). An example would be a client trusting a logistics company in packaging and shipping their product to the end customer in the fashion agreed upon during on boarding. Competence trust stems from the belief that a given partner has the managerial and technical capabilities to perform a task (Ireland, 2006). Imagine a company in search for choosing a logistics company to ship their product. Most likely, the company will choose a logistics company who have a good reputation in shipping product to the end customer in a timely and professional manner. The company trust the logistic partner because they have a good idea that the logistic company will perform well in their tasks. Last, goodwill trust exists when partners are willing to act in ways exceeding stipulated contractual agreements (Ireland, 2006). Goodwill trust typically occurs when partners exceed the other party expectations in a task.

\subsection{Bridging the Gap: Performance}

Through past studies, we know that reliability and power is needed for cultural competitiveness (Ireland, 2006). However, for a supply chain to have an opportunity to enter and succeed in a competitive market, they must have good performance. To perform well, there must be strong operations and processes in place to best fit the overall goal and objective of the supply chain. Now that we understand reliability and power in relationships help strengthen a supply chain, we can now integrate trust as the gap that connects both reliability and power in a supply chain. Reliability is needed to trust a relationship as power can only be granted through trust that is founded from reliability.

In a supply chain, when testing a process or machine, supply chain management first test the reliability of the process or machine. If the process or machine is reliable, then SCM adapts and implement that process or machine. When a process or machine is implemented, we assume to trust the function as it is best fit for the supply chain. Once a process or machine is reliable and trusted, we can then safely say that function has power. Performance is inclined because the process and machine used has prove to be effective and work efficiently to produce positive results.

\section{Propositions}

Trust and power are dependent of reliability. Reliability is needed to carry out an activity and built overtime. Power is the influential dimension that promotes decision making in a supply chain. Without reliability and power, a supply chain cannot move forward in making critical decisions that affect not only performance but the competitive reputation in an industry market.

Proposition 1: Reliability and power is needed to carry out an activity in a supply chain to increase performance. 
Trust is the gap between both reliability and power. To trust a process that is recommended through a relationship, individuals must consider the actor or process to be trustworthy. Reliability and power serve the purpose of experience, commitment, and quality. Once a relationship or process is trusted, power can then be granted because we trust that the process is reliable which gives it power.

Proposition 2: Trust bridge the gap between power and reliability.

Proposition 3: Reliability is positively related to trust, leading to higher power.

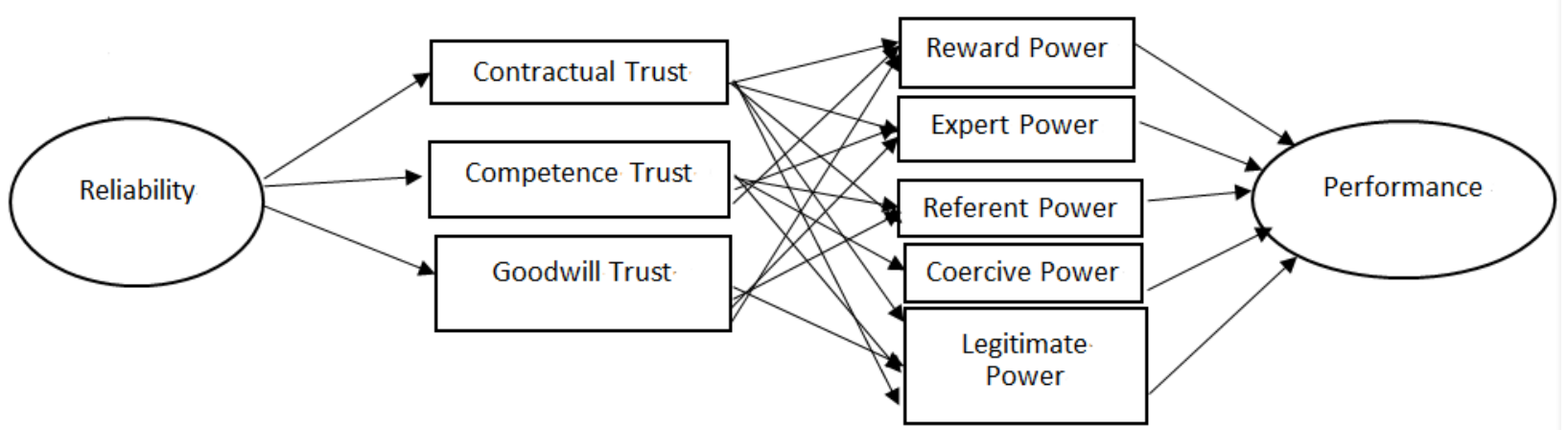

Figure 1. The figure above demonstrates how reliability and power is bridged by trust in the supply chain to better strengthen performance

\section{Limitations}

The first limitation of this study is that although supply chain performance is reflective of power, trust, and reliability, different firms require different levels of each variable (Ireland, 2006). Because of this, it is imperative for a supply chain firm to decide what level of each variable affects and contributes to their firm. For instance, a small supply chain firm may use higher levels of trust than larger firms. This could be a result of a narrower communication channel involving few participants, enhancing reliability. A smaller supply chain firm may also include low levels of power, while larger firms include high levels of power. This statement could be reversed depending on the goal and purpose of the supply chain firm. Therefore, reliability in reference to power and trust will differ as it is dependent on the levels of power and trust the firm produces. The second limitation of the study is that although this a proposal for future research, testing involving observation and survey data will help strengthen the study current findings and proposals. The study simply provided an extensive literature review with proposals with hopes of a longitudinal extensive study in the future.

\section{Future Research}

For future research, it would be beneficial to complete a longitudinal study to test the different levels of trust, power, and reliability, and how a firm determine if low or high levels are needed to implement a good performing supply chain. Because there are many levels of both power and trust, we can imagine how different firms would use a best fit level of each variable and apply to their supply chain. A longitudinal study is implied due to performance being evaluated after a process has been completed and tested.

Another study could examine how variation play an important concept in the supply chain. Including statistical data will help supply chain detect error more efficiently.

This study could also connect with a theory such as the resource dependency theory or agency theory as both theories apply to power but in different perceptions. When implying a theory, in terms of management, a theory could break down the components of reliability. Reliability could be broken down into supplier and buyer. When breaking reliability into supplier and buyer components, we can then observe performance at a better perspective and understand reliability from the two points of views as it would have a different affect on performance. 


\section{Conclusion}

The supply chain is crucial to a firm success. Performance plays a major role in the success of a supply chain. Understanding how trust, power, and reliability contributes to the performance of a supply chain will better lead firms in being creative in the relationships and processes established. This study served the purpose of exposing the gap between reliability and power by describing each variable and its contribution to the supply chain.

With the proposals implemented, reliability and power are needed to carry out an activity in a supply chain to increase performance. However, to increase performance, the operations being carried out must have a level of trust that bridge the gap between reliability and power. With the trust of people and systems, power can be established because the actors then know that the people or process is trustworthy, making it a reliable source by giving it power. This study was a short conceptual study with a model to give a brief description of how reliability and power is bridged by trust to increase higher work performance in a supply chain.

\section{References}

Amirul Mustofa, A. D. (2017). Analysis of regionalization of a number of referral patients' visits and satisfaction of the national health care insurance at the preferred further treatment health care facilities in the regency of bantul, Indonesia. International Journal of Scientific and Research Publications, 77.

Benton, M. M. (2000). Power influences in the supply chain. Journal of Business Logistics, 2-73.

Blache, K. M. (2017, October 25). Link Relaibility into Supply Chains. Retrieved from Efficient Plant: https://www.efficientplantmag.com/2017/10/link-reliability-supply-chains/

Cox, A. I. (2002). Supply Chains, Markets and Power, Mapping buyer and supplier power regimes. Routledge studies in Business Organization and Networks. https://doi.org/10.4324/9780203299272

Flynn, Z. H. (2008). We've got the power! How customer power affect supply chain relationships. Business Horizons, 169-174. https://doi.org/10.1016/j.bushor.2008.01.009

Hanf, V. B. (2011). Power and supply chain management - insights from Russia. GEWISOLA.

Ketchen, F. R. (2015). Special Topic Forum on Power in Supply Chain Management. Journal of Supply Chain Managment, 2.

Lopez, E. (2017, January 2). What is a supply chain?. Retrieved from Supply Chain Dive: https://www.supplychaindive.com/news/what-supply-chain-definition/433123/

R. Duana Ireland, J. W. (2006). A multi-theroretic perspective on trust and power in strategic supply chains. Journal of Operations Management , 16.

Rouse, M. (2013, March). Tech Target. Retrieved from What is a Supply Chain: https://whatis.techtarget.com/definition/supply-chain

SME, S. (2003, November 5). Trust in Supply Chain Relationships: What Does It Mean to Trust? - Part I. Retrieved from Supply Chain Resource Cooperative: https://scm.ncsu.edu/scm-articles/article/a-sustainable-energy-platform-for-the-eu-and-the-world-2

SME, S. (2017, April 2). What is Supply Chain Management (SCM). Retrieved from NC STATE UNIVERSITY: https://scm.ncsu.edu/scm-articles/article/what-is-supply-chain-management-scm

Supply Chain Management Best Practices: Realibility. (2016, January 6). Retrieved from PLS Logistic and Service: https://www.plslogistics.com/blog/supply-chain-management-best-practices-reliability/

What is Reliability in Supply Chain Management? (2016, January 6). Retrieved from PLS Logistics: https://www.plslogistics.com/blog/supply-chain-management-best-practices-reliability/

Zhao, H. F. (2008). The impact of power and relationship commitment on the integration between manufactures and customers in a supply chain. Journal of Operation Management, 368-388. https://doi.org/10.1016/j.jom.2007.08.002 